\title{
A RECUSA DE TRATAMENTO MÉDICO POR CRIANÇAS E ADOLESCENTES: UMA ANÁLISE A PARTIR DA COMPETÊNCIA DE GILLICK
}

\section{THE REFUSE OF MEDICAL TREATMENT BY CHILDREN AND ADOLESCENTS: AN ANALYSIS FROM THE GILLICKS COMPETENCE}

\author{
${ }^{1}$ Marina Carneiro Matos Sillmann \\ ${ }^{2}$ Maria de Fátima Freire de Sá
}

\section{RESUMO}

Os debates acerca da recusa de tratamento médico surgem do exercício da autonomia do paciente. Em relação a esta possibilidade aplicada para crianças e adolescentes a situação se mostra complexa porquanto, apesar de terem seus direitos da personalidade resguardados, não possuem a capacidade civil para tomada de decisões. Tais questões passam pela análise da extensão e limites da autoridade parental em face da autonomia da criança e do adolescente. A tomada de decisão pelos pais deve observar, de um lado, o dever de cuidado inerente à autoridade parental e, de outro, a autonomia do menor nos limites delineados pela ordem jurídica, em especial o Estatuto da Criança e do Adolescente. Como pessoa humana em processo de desenvolvimento, a criança e o adolescente têm direito à liberdade, ao respeito e à dignidade, entre outros (art.15, Estatuto da Criança e do Adolescente). Nesse sentido, o cotidiano nos apresenta casos como Hannah Jones e Reece Puddington, em que, apesar da tenra idade, optaram pela recusa de tratamento do câncer. Este trabalho pretende analisar o Caso Gillick, ocorrido na Inglaterra, que trouxe a competência de Gillick como parâmetro para se apurar o discernimento de pessoa menor de dezesseis anos, verificando a possibilidade de sua utilização pelo ordenamento jurídico brasileiro. Para concretizar o presente estudo, utilizarse-á a pesquisa teórica. Por sua vez, o método a ser empregado na pesquisa será através do estudo monográfico e legislativo de obras que trataram a temática da recusa de tratamento médico por crianças e adolescentes. A técnica a ser empregada na realização da pesquisa será de análise temática e textual, obtendo conceitos e teorias já formuladas sobre o assunto e captando as problemáticas mais relevantes do mesmo.

Palavras-chave: Competência de gillick, Recusa de tratamento médico, Criança e adolescente, Autoridade parental

\section{ABSTRACT}

Debates about the refusal of medical treatment emerge from the exercise of patients autonomy. In relation to this possibility applied to children and adolescents the situation proves complex because, although they have their personality rights safeguarded, lack the legal capacity to make decisions. Such questions go through the analysis of the extent and limits of parental authority in the face of the child and adolescent autonomy. The parental decisionmaking must observe, on the one hand, the duty of care inherent in parental

\footnotetext{
${ }^{1}$ Mestre em Direito na Pontifícia Universidade Católica de Minas Gerais - PUC, Minas Gerais, (Brasil) Email: tutortreinamneto@gmail.com

${ }^{2}$ Doutor em Direito pela Universidade Federal de Minas Gerais - UFMG, Minas Gerais, Brasil. Professora do Programa de Pós Graduação em Direito da Pontifícia Universidade Católica de Minas Gerais - PUC, Minas Gerais, (Brasil)
} 
authority and on the other, the autonomy of the smaller within the limits outlined by the law, in particular the Statute of Children and Adolescents. As human beings in the development process, the child and adolescent have the right to liberty, respect and dignity, among others (Art.15, Statute of Children and Adolescents). In this sense, this study presents us with cases like Hannah Jones and Reece Puddington, where, despite the young age, opted for refusing cancer treatment. This paper analyzes the Gillick case, occurred in England, which brought the Gillicks Competence as a parameter to determine the discernment of person under sixteen years, verifying the possibility of their use by Brazilian law. To realize this study, will be used to theoretical research. In turn, the method to be used in the search will be through the monographic study and legislative works that addressed the issue of refusal of medical treatment for children and adolescents. The technique to be employed in carrying out the research will be thematic and textual analysis, obtaining concepts and theories already formulated on the subject and capturing the most relevant issues of the same.

Keywords/Palabras-claves/Mots-clés: Gillicks competence, Refuse of medical treatment, Children and adolescents, Parental authority

\section{INTRODUÇÃO}

As discussões sobre a recusa de tratamento médico surgem do exercício da autonomia privada do paciente. Em relação a esta possibilidade aplicada em crianças e adolescentes a situação está longe de ser simples, eis que, apesar de terem seus direito da personalidade resguardados, não possuem autonomia plena para a tomada de decisões sobre seu próprio corpo.

Casos como Gillick contra West Norfolk e Wisbech Area Health Authority demonstram que o critério etário de incapacidade não se deve mostrar absoluto. Mas, se há discernimento para a recusa de tratamento médico, qual a abrangência desta possibilidade? Em outras palavras, seria possível determinar em que situações a recusa de tratamento médico por parte de crianças e adolescentes seria considerada legítima?

A mídia traz à baila situações emblemáticas como a de Hannah Jones, uma jovem de treze anos que, desde os quatro, sofria de leucemia mieloide aguda (um tipo raro de câncer). Em razão do câncer, o coração de Hannah começou a falhar, sendo necessário um transplante para garantir sua sobrevivência. A jovem e seus pais foram informados dos benefícios e riscos que o transplante poderia trazer ao seu corpo. Ciente disso, Hannah se manifestou contrária ao recebimento de um novo coração, recebendo apoio de seus pais. A equipe médica, em um primeiro momento, não aceitou a decisão de Hannah e cogitou a possibilidade de forçar o transplante mediante autorização judicial. $\mathrm{O}$ caso não foi ao judiciário porque a junta médica 
entendeu, após avaliação psicológica de Hannah pela assistente hospitalar, que a jovem tinha compreensão de sua escolha em recusar transplante. Neste caso, houve concordância dos pais e apoio da equipe médica com a decisão de Hannah. E se não houvesse? (SÁ, MOUREIRA, 2015).

Outro caso em que o discernimento aparece como chave da questão é o de Reece Puddington, um inglês de onze anos. O menino, desde seus cinco anos de idade, enfrenta o neuroblastoma (tumor cerebral) e manifestou em sua página do Facebook o desejo de interromper o tratamento. A mãe, apesar de desejar que Reese continuasse com o tratamento, respeitou sua decisão e o levou para casa. O jovem faleceu, mas cumpriu vários dos desejos expostos em sua bucket list. Este caso também demonstra o respeito à concepção de vida boa de cada um. (PARRY, 2014).

O que chama a atenção nas histórias acima relatadas é a idade de seus protagonistas, bem como o respeito de suas decisões em razão da constatação do discernimento. Crianças e adolescentes podem recusar tratamento médico, ainda que isso as leve à morte? A resposta não é algo simples de se obter. Trataremos abaixo do Caso Gillick. Sua relevância se dá em razão do debate travado acerca da competência de menores para aderir a tratamento médico, mais especificamente, acerca do uso de contraceptivos. O Caso Gillick, não aborda a recusa de tratamento médico, no entanto, transpondo o caso para o Direito brasileiro, o que pretendemos abordar é a possibilidade de, a partir deste case, pensarmos em recusa de tratamento médico por parte de crianças e adolescentes que tenham discernimento.

Para tanto, faz-se pertinente o estudo da autoridade parental no que toca às questões de cunho existencial com o intuito de apurar seus limites. Com o fim de ilustrar esta questão, abordaremos a estória de Adam Henry (A balada de Adam Henry), inspirado em casos presididos pelo Juiz Alan Ward, na Inglaterra.

Em outro momento, abordaremos os aspectos civis e constitucionais da recusa de tratamento médico e, em seguida, analisaremos esta possibilidade aplicada à crianças e adolescentes, utilizando como critério a Competência de Gillick.

O presente estudo se justifica em razão do momento atual do Direito Civil pátrio, de releitura de seus institutos clássicos, como é a teoria das incapacidades por idade à luz do princípio da dignidade da pessoa humana, fundamento da República, consagrado pela Constituição de 1988. 


\section{O CASO GILLICK E A COMPETÊNCIA DE GILLICK}

O Caso Gillick ${ }^{1}$ data de 1986 e representa um marco na conquista do direito de adolescentes e crianças receberem informações médicas, independentemente da autorização de seus pais ou responsáveis.

O Departamento de Saúde e de Segurança Social do Reino Unido emitiu, em 1974, a circular HSC(IS)32, dirigida aos profissionais da área da saúde sobre planejamento familiar, revista em 1980. A seção $G$ trata dos cuidados médicos relativos aos jovens.

A seção $G^{2}$ aponta que as consultas clínicas devem ser disponibilizadas para pessoas de todas as idades. Sugere ainda um tratamento menos formal aos jovens, feito por uma equipe com experiência. A Circular sugere ao médico que aconselhe o jovem a envolver seu representante legal.

Dentre as atribuições do médico está, também, o aconselhamento sobre contracepção, ainda que sem o consentimento dos pais. A justificativa é a confidencialidade da consulta médica e a relação de confiança que deve ser construída entre médico e paciente, além do risco de expor os jovens às doenças sexualmente transmissíveis ou gravidez indesejada devido à falta de informação. Portanto, configura-se como atribuição médica a avaliação acerca da prescrição de métodos contraceptivos à criança ou adolescente.

A senhora Gillick, mãe de cinco filhas, inconformada com o disposto na circular, requereu às autoridades locais a proibição de fornecer informações referentes a métodos contraceptivos às suas filhas, até que completassem a idade de dezesseis anos ou apenas mediante sua autorização. Após ver seu pedido negado, a senhora Gillick ingressou com ação contra West Norfolk e Wisbech Area Health Authority, justificando que fornecer informações sobre métodos contraceptivos sem autorização dos pais viola o direito à autoridade parental. O juiz entendeu que o fornecimento das informações, por si só, não incentivava a prática de atos sexuais por menores de dezesseis anos e que o interesse dos pais sobre a vida dos filhos não corresponde a um direito, mas a um dever ou uma responsabilidade.

A mãe recorreu junto ao Tribunal de Recursos, que, por sua vez, considerou a circular ilegal, fundamentando que menores de dezesseis anos não poderiam receber aconselhamento sexual sem autorização de seus pais ou responsáveis. De outro lado, o Departamento de Saúde recorreu junto à House of Lords.

1 As informações jurídicas sobre o caso foramretiradas do site: http://www .cirp.org/library/legal/UKlaw/gillickvwestnorfolk 1985/.Acessoem 20dejun.de2015.Tradução livre.

2REVISED SECTION G--THE YOUNG: Clinic sessions should be available for people ofall ages, but it may be helpful to make sepa rate, less formul arangements foryoung people. The staffshould be experienced in dealing with young people and their problems. There is widespread concern about co unselling and treatment frchildrenunder 16 . Special care is needed not to undermine parental responsibility and family stability. The Department would therefore hope that in any case whereadoctororotherprofssional worker is approached by a person under the age of 16 for advice in these matters, the doctor, or other professional, will always seek to 
Lorde Templeman apontou que autoridade parental não é algo absoluto e na medida em que a criança se desenvolve, sua necessidade de proteção reduz e, gradativamente, as próprias escolhas são feitas, de acordo com a compreensão de mundo e o desenvolvimento intelectual. Lorde Brandon entendeu que o médico possui competência para avaliar o alcance da criança ou do adolescente quanto ao aconselhamento sexual.

persuade the child to involve the parent or guardian (or other person in loco parentis) at the earliest stage of consultation, and will proceed from the assumption that it would be most unusual to provide advice about contraception without parental consent. It is, however, widely accepted that consultations between doctors and patients are confidential and the Department recognises the importance which doctors and patients attach to this principle. It is a principle which applies also to the other professions concerned. To abandon this principle for children under 16 might cause some not to seek professional advice at all. They could then be exposed to the immediate risks of pregnancy and of sexually-transmitted disease, as well as other long-term physical, psychological and emotional consequences which are equally a threat to stable family life. This would apply particularly to young people whose parents are, for example, unconcerned, entirely unresponsive, or grossly disturbed. Some of these young people are away from their parents and in the care of local authorities or voluntary organisations standing in loco parentis. The Department realises that in such exceptional cases the nature of any counselling must be a matter for the doctor or other professional worker concerned and that the decision whether or not to prescribe contraception must be for the clinical judgment of a doctor.

A corte apontou ainda que a autoridade parental não existe para atender os interesses dos pais, mas sim, os interesses da criança. Esta afirmação pode ser compreendida no sentido de que a autoridade parental consiste em um dever dos pais para com a criança e não em um direito dos pais sobre a criança.

A House of Lords, após debater o caso, decidiu pela licitude da circular e, desde então, é permitido ao menor de dezesseis anos consentir em questões relacionadas a tratamento médico, independentemente de autorização do representante legal, desde que seja considerado apto para tanto pelo profissional da saúde.

O Caso Gillick deu origem ao termo Competência de Gillick (Gillick Competence), que consiste na possibilidade de o menor aderir a tratamento médico, independentemente do consentimento dos pais. Para apurar se a criança ou o adolescente têm a compreensão necessária para tomada de decisões, foram criados os denominados testes Gillick (teste de Lorde Scarman e Fraser Guidelines ), elaborados por dois dos juízes que julgaram a questão.

Lorde Scarman propôs em seu voto que "o direito dos pais de determinar se o menor de dezesseis anos será sujeito ou não a um tratamento médico termina se e quando a criança atinge inteligência e discernimento suficientes que a tornem capaz de compreender por completo o que lhe é proposto." (GILLICK X WEST NORTHFOLK, 1985). Portanto, inteligência e discernimento são elementos subjetivos que, para Lorde Scarman, devem ser avaliados pelo médico diante de cada situação.

Jane Fortin comenta a proposta de Lorde Scarman: 
[...] A fórmula para apurar a competência de Gillick elaborada por Lorde Scarman, para todos os efeitos, proporciona um excelente método pelo qual os médicos podem identificar os pacientes adolescentes que são suficientemente maduros para tomar decisões responsáveis. Ele permite que um médico adote uma abordagem muito mais inteligente para o conceito de capacidade do que só depender da idade ou até mesmo na evidência de pesquis a sobre o crescimento cognitivo das crianças. O teste é funcional - o menor tem capacidade de compreender, e, portanto, concordar com o procedimento, dependendo da gravidade do que é proposto. Mesmo assim, a dificuldade implícita no teste de avaliação da competência de Gillick é sua enganosa simplicidade. Na verdade, foi apenas no contexto de uma prestação de aconselhamento e tratamento contraceptivo que essa orientação foi desenvolvida. Em contextos médicos mais amplos, o teste de Gillick deixa os médicos sem diretrizes claras sobre as circunstâncias em que se pode aceitar que um adolescente possa consentir em um determinado procedimento, sem envolver seus pais. (FORTIN, ANO, p.148, tradução livre) ${ }^{4}$.

\footnotetext{
3،[ ...]the parental right to determine whether or not their minor child below the age of 16 will have medical treatment terminates if and when the child achieves a sufficient understanding and intelligence to enable him or her to understand fully what is proposed."

${ }^{4}$ [...] Lord Scarman's Gillick competence formula, to all intents and purposes, provides an excellent method whereby doctors can identify those teenage patients who are sufficiently mature to reach responsible decisions for themselves. It allows a doctor to adopt a far more intelligent approach to the concept of capacity than one
}

A proposta de Lorde Fraser consiste na apuração de cinco elementos:

(1) estar convicto de que o jovem compreende o aconselhamento/tratamento; (2) não deve forçar o jovem a informar os pais ou a dar-lhe autorização para tal; (3) deve suspeitar que o jovem vai, quase certamente, começar ou continuar a ter relações sexuais com ou sem proteção; (4) deve suspeitar que, se o jovem não receber tratamento contraceptivo, a sua saúde física ou mental poderá sofrer danos; (5) deve considerar ser do melhor interesse do jovem receber aconselhamento ou tratamento contraceptivo sem o conhecimento ou consentimento dos pais. (ABREU, 2012, p. 16).

As Guidelines de Lorde Fraser também exigem uma avaliação subjetiva do menor para apurar se há discernimento e acrescenta o fator 'risco' do jovem estar envolvido ou prestes a se envolver em relações sexuais. Além da compreensão das informações, há o perigo de dano para a saúde do jovem em razão da falta de conhecimento sobre métodos contraceptivos.

Os parâmetros da Competência de Gillick foram mencionados no livro "A balada de Adam Henry", que dentre outras questões, aborda a recusa de tratamento médico por adolescente. 


\section{AUTORIDADE PARENTAL X DIREITO AO EXERCÍCIO DA AUTONOMIA POR MENORES DE DEZOITO ANOS}

\subsection{A balada de Adam Henry: autoridade parental e a autonomia da criança e do adolescente}

Encontrar o limite entre o dever de cuidado dos pais e o respeito à vontade de uma criança ou de um adolescente não é algo fácil de obter, como já dissemos.

Ian McEwan escreveu o romance A Balada de Adam Henry inspirado em dois casos presididos pelo Juiz inglês Alan Ward. O primeiro, quando ele atuou como membro do Tribunal Superior, em 1990, e o segundo como membro do Tribunal de Recursos, em 2000.

A obra tem como personagem de destaque, Fiona, juíza do Tribunal Superior e responsável por julgar processos de direito de família. Dentre os vários casos difíceis levados

merely relying on age or even on the research evidence on children's cognitive growth. The test is a functional one - whether the minor has capacity to comprehend, and therefore consent to, the procedure depends on the gravity of what is proposed. Even so, the difficulty implicit in the test for assessing Gillick's competence is it's deceptive - simplicity. Indeed, it was only in the context of the provision of contraceptive advice and treatment that such guidance was developed further. In more general medical contexts, Gillick's left doctors with no clear guidelines over the circumstances in which they can accept that an adolescent can consent to a particular procedure without involving his or her parents.

a julgamento estava o de Adam Henry, um jovem de dezessete anos, a três meses de completar dezoito, que sofria de leucemia e precisava de uma transfusão de sangue. Ele e seus pais se recusavam a dar o consentimento porque eram Testemunhas de Jeová.

O autor da ação foi o Hospital Geral Edith Cavell que pedia autorização para tratar o rapaz ainda que contra sua vontade. Segundo o Hospital, o tratamento seria usual: dois medicamentos atacavam diretamente as células de leucemia e outros dois atingiam a medula óssea, impedindo a produção de hemácias, leucócitos e plaquetas, gerando a necessidade de transfusão de sangue. O demandante deixou claro que o único tratamento para esta consequência trazida pelos medicamentos era a transfusão de sangue.

Os argumentos trazidos pelo advogado dos pais de Adam vertiam no sentido de ser direito fundamental a escolha do tratamento médico e que, apesar da idade de Adam, sua vontade era livre e competente. O Advogado suscitou ainda o Caso Gillick tendo afirmado ser o jovem detentor da "competência de Gillick".

O pai de Adam explicou a razão para a recusa da transfusão de sangue: a proibição presente no Gênesis, no Levítico e nos Atos. Misturar sangue com o de outra pessoa significava contaminação. 
Adam, representado por sua guardiã, afirmou, por escrito, ter ideias próprias e que a decisão de recusa da transfusão de sangue foi tomada com independência. Em outras palavras, era uma decisão sua e não imposta por seus pais. Ressaltou assim que, ao seguir a religião escolhida por seus pais, concordava com seus dogmas e estava disposto, inclusive, a morrer por eles.

Fiona, buscando compreender o caso, decidiu ir até o hospital conversar com Adam para avaliá-lo. O contato impressionou a juíza em razão da vivacidade e da clareza que possuía o jovem. Fiona o alertou novamente das possibilidades apresentadas pelos médicos, caso Adam não recebesse a transfusão: morte ou recuperação parcial com sequelas como cegueira, danos cerebrais, entre outros. Por fim, perguntou a Adam: "Será que agradaria a Deus ter você cego ou mentalmente incapaz, ou fazendo diálise pelo resto da sua vida?" (McEWAN, 2015, p.100)

Fiona estava segura de que a pergunta ultrapassava seus deveres como juíza, mas a conversa desenrolava bem. Ao final, afirmou a Adam que obteve aquilo que precisava e que ele deixara bem claro sua vontade.

Contudo, a decisão não contemplou a vontade de Adam. A transfusão de sangue foi determinada;

\begin{abstract}
Ele é sem dúvida uma criança excepcional. [...]. Ele tem uma capacidade de compreensão excepcional para um jovem de dezessete anos. Mas creio que possui um entendimento limitado da provação que deve confrontar, do pavor que o invadiria à medida que seu sofrimento e sua impotência aumentassem. [...]. Entretanto, em última análise, não me deixo influenciar pelo fato de que ele tenha ou não a compreensão absoluta de seu estado. [...]. Entendo 'bemestar' como englobando 'felicidade' e 'interesses'. [...] Como já observei, ele a expressou [vontade] claramente a mim, como o fez seu pai perante esta corte.[...] É um direito fundamental dos adultos recusarem qualquer tratamento médico. A está próximo da idade em que pode tomar uma decisão por sua conta e risco.[...] $\mathrm{O}$ fato de que seus pais estão preparados para sacrificar um filho muito querido por causa de sua fé revela o poder da crença a que as testemunhas de Jeová obedecem. [...] Não creio que a mente de A e suas opiniões lhe pertençam inteiramente. Durante toda a infância ele esteve exposto sem interrupção a uma visão do mundo monocromática e poderosa, a cujo condicionamento não poderia escapar. [...] Esta não foi uma questão simples de resolver. Ponderei cuidadosamente a idade de $\mathrm{A}$, o respeito devido à sua fé e a dignidade do indivíduo contida no direito de recusar tratamento. A meu juízo, sua vida é mais preciosa do que essa dignidade.(McEWAN, 2014, p.

114-115)
\end{abstract}

Adam recebe a transfusão de sangue, e retoma sua rotina. O jovem, apesar de saudável e inteligente, se vê transtornado em razão de diversos questionamentos sobre sua fé e forma de vida anterior, bem como das novas possibilidades que não seguir a religião de seus pais traria. 
Passado algum tempo, a doença retorna ao corpo de Adam, trazendo novamente a necessidade de uma transfusão de sangue. Ele, naquele momento, capaz aos olhos da lei, recusa o tratamento e vem a óbito.

A decisão de Fiona consagra a vida como valor. Porém foi baseada em sua compreensão de mundo. Para a juíza a vida se sobrepõe ao exercício da liberdade religiosa. Ela esperava que Adam experimentasse a vida além dos rígidos limites trazidos por sua religião. Foi a mais acertada? Entendemos que não. Apesar de a religião ter sido uma escolha de seus pais, Adam demonstrou que compartilhava da fé. Fiona ignorou que ser Testemunha de Jeová era algo que fazia parte da biografia, da construção da pessoalidade do jovem.

O caso ilustra a questão do alcance da autoridade parental como uma forma de construção dos valores da criança e do adolescente. Interpretando a obra, percebemos que, se em um primeiro momento tratou-se de imposição religiosa, posteriormente, afigurou-se escolha de Adam, que elegeu para si os valores religiosos de seus pais. A medida adotada pela juíza faria sentido se Adam não dispusesse de discernimento. Assim, uma transfusão de sangue, nesse contexto, garantiria o exercício de uma autonomia futura.

\subsection{AUTORIDADE PARENTAL: CONCEITO E LIMITE}

O Caso Gillick suscita o debate do limite do direito dos pais sobre os filhos. A senhora Gillick entendeu ser direito seu decidir quando suas filhas receberiam orientações sobre cuidados contraceptivos. Contudo, como bem ponderou Lord Templeman, os direitos dos pais $^{5}$ sobre os filhos são gradativamente reduzidos na medida em que os menores adquirem compreensão de mundo (GILLICK X WEST NORTHFOLK, 1985).

Quando os pais decidem em nome dos filhos, não se está diante de uma situação de autonomia, mas sim de um dever legal de cuidado: o exercício da autoridade parental. Dentre os mais diversos aspectos desse múnus, o que se mostra relevante para este estudo é a busca de seus limites. Em outras palavras, qual é o limite do dever de cuidado dos pais para com seus filhos? Até que ponto podem decidir em nome destes?

Walsir Edson Rodrigues Junior e Renata Barbosa de Almeida apresentam a definição deste instituto utilizando a nomenclatura adotada pela legislação civilista brasileira: "entendese por poder familiar a autoridade jurídica dos pais sobre os filhos menores no propósito de presunção e proteção dos interesses destes.” (2012, p. 447).

A Constituição brasileira de 1988 estabelece em seu art. 229, o dever dos pais de assistir, criar e educar os filhos menores. No cumprimento destes deveres os pais, 
constantemente, tomam decisões capazes de moldar a vida de seus filhos, como qual escola ele será matriculado, a educação religiosa e os cuidados com a saúde.

O Código Civil brasileiro, em seu art. 1.634, estabelece como poder-dever dos pais para com os filhos os relacionados à educação e à criação, à companhia e à guarda, a negação ou o consentimento para casamento, a nomeação de tutor e de representá-los ou assisti-los, entre outros. O Estatuto da Criança e do Adolescente traz as responsabilidades paterno-filiais em seu art. 22 .

Podemos afirmar assim que a autoridade parental abarca decisões sobre questões existenciais da vida dos filhos:

\begin{abstract}
Diante das diretrizes constitucionais e estatutárias que ressaltam a função promocionaldo Direito, o relacionamento entre genitores e o filho passou a ter como objetivo maior tutelar sua personalidade e, portanto, o exercício dos seus direitos fundamentais para que possa, neste contexto, edificar sua dignidade enquanto sujeito. A autoridade parental, neste aspecto, foge da perspectiva de poder e de dever, para exercer sua função de instrumento facilitador da construção da autonomia responsável dos filhos. Nisso consiste o ato de educá-los, decorrente dos princípios da Paternidade e Maternidade Responsável, e da Doutrina da Proteção Integral, ambos com sede constitucional, ao fundamento de serem pessoas em fase
\end{abstract}

$\mathrm{Na}$ medida em que se desenvolvem, os pais devem permitir aos filhos que tomem suas decisões nestes campos. Não se pode impor que o filho ateu vá à Igreja ou mesmo que não conteste os valores da religião de seus pais, por exemplo. $\mathrm{O}$ alcance da autonomia do menor é progressivo. Assim:

\begin{abstract}
O encargo dos pais é reger a formação dos menores, não se esquecendo, porém, de que a decisão sobre temas sobre os quais já tenham adequado discernimento há de ser deixada a estes últimos. Imprescindível que os pais resistam à tentativa de fazer, pelos filhos, o julgamento das opções de vida e, ainda, a eleição de qualquer delas. Isso jamais corresponderia ao fomento da liberdade e da responsabilidade. Em última instância: os menores tornam-se os sujeitos em questão, ocupando lugar de destaque nessa relação parental enquanto sujeitos promotores do seu próprio processo de constituição pessoal. O berço thes confere a existência, mas a vida há de ser obra deles mesmos. Os pais hão de respeitar este espaço. (ALMEIDA, RODRIGUES JUNIOR, 2012, p. 449).
\end{abstract}

No caso Gillick, a Corte entendeu que a mãe ultrapassou seus deveres parentais ao impor que suas filhas apenas recebessem os cuidados contraceptivos apenas quando ela julgasse ser adequado. Ela ignorou o desenvolvimento de cada filha, bem como, seu direito à liberdade sexual. O limite da autoridade parental do caso citado, conforme fica evidenciado a partir da leitura do julgado, é a compreensão das jovens sobre os fatores inerentes à sexualidade.

\footnotetext{
${ }^{5}$ É utilizado no julgado o termo parents rigths, contudo, acredita-se que o sentido da expressão é de um dever dos pais com os filhos e não de um direito sobre estes de desenvolvimento, o que lhes garante prioridade absoluta.
} (TEIXEIRA, 2005, p.130-131). 
Portanto, a autoridade parental representa um dever, um múnus dos pais em relação a seus filhos com o intuito de cuidado, proteção e auxílio ao desenvolvimento social e intelectual destes. Em outras palavras, um apoio para o amadurecimento de seu discernimento. Este instituto visa à promoção dos melhores interesses dos filhos ainda que estes possam ser opostos aos interesses dos pais. Assim, o melhor interesse do menor, bem como seu amadurecimento, representam limites ao exercício da autoridade parental. Entendemos que a ação dos responsáveis é legítima quando importar em benefício para o

menor.

O princípio do melhor interesse do menor e da autonomia progressiva foi consolidado na Convenção dos Direitos da Criança de 1989, assinada pelos Estados das Nações Unidas, exceto Estados Unidos e Somália, tendo o Brasil a ratificado (Decreto $\mathrm{n}^{\circ}$ 99.710 de 1990). Cuida-se de instrumento responsável por alterar a visão jurídica da criança, passando esta a ser considerado um ser em desenvolvimento, vulnerável, mas dotado de capacidade progressiva, sendo sujeito ativo na construção de sua biografia e igual em dignidade ao adulto (MARTINS, 2009, p. 87). Cumpre ressaltar que, nos termos da Convenção, criança é todo aquele menor de dezoito anos de idade.

$\mathrm{O}$ art. $3^{\circ}$, de forma expressa, apresenta o princípio do melhor interesse da criança: 'todas as ações relativas às crianças, levadas a efeito por instituições públicas ou privadas de bem estar social, tribunais, autoridades administrativas ou órgãos legislativos, devem considerar, primordialmente, o maior interesse da criança".

Sobre a nomenclatura do supracitado princípio, temos que:

\begin{abstract}
No Brasil, apesar de no artigo $3^{\circ}$ os tradutores terem optado pela expressão "maior interesse", ao longo do texto há também menção aos "melhores interesses". Se não bastasse a variação de nomenclatura presente no decreto que promulgou a Convenção no Brasil, a Lei $n^{\circ} 8.069 / 90$ apresentou o mesmo problema. A Lei ${ }^{\circ}$ 12.010/2009, ao modificar o Estatuto da Criança e do Adolescente, introduziu um terceiro termo no Direito brasileiro: "interesse superior/superior interesse". Em que pese a miscelânea de expressões existente no ordenamento jurídico pátrio, independente se "maior", "melhor" ou "superior", objetivo é o mesmo: salvaguardar os direitos das crianças e dos adolescentes com a maior efetividade possível. (FERREIRA, VIEIRA, 2013, p.244)
\end{abstract}

Podemos entender que o princípio do melhor interesse é alcançado quando se concilia os interesses dos pais e dos filhos. A tomada vertical de decisão, ou seja, desconsiderando a vontade da criança consiste em retirar a eficácia normativa do princípio (FERREIRA, VIEIRA, 2013, p.248). 
$\mathrm{O}$ art. 12 da Convenção traz a autonomia progressiva da criança ao assegurar-lhe o direito de expressar suas opiniões sobre todos os assuntos relacionados ao seu interesse, levando-as em consideração sua idade e maturidade. Também assegura o direito da criança de ser ouvida em processo judicial e administrativo que the afete.

Ao comentarem o preâmbulo da Convenção, Fiorelli e Mangini apontam o destaque conferido à autonomia progressiva da criança: "remete-se, aqui, a um desenvolvimento em direção à formação de indivíduos capazes de assumir seus destinos, realizar suas escolhas com segurança e respeitando os ideais de igualdade e fraternidade no seu convívio social" (FIORELLI, MANGINI, 2015, p. 148).

Os arts. 15 e 16 do Estatuto da Criança e do Adolescente (Lei no 8.069 de 1990) asseguram o direito à liberdade ao respeito e à dignidade. Assim, entendemos que tais direitos, em especial a dignidade da criança e do adolescente, se efetivam quando respeitados os valores, crenças e opiniões do menor. Isso não significa que todas as suas vontades deverão ser cumpridas, mas sim que, enquanto seres humanos em desenvolvimento têm o direito a participar das decisões de questões que envolvam sua vida, sendo ampliado seu poder de decisão na medida em que amadurecem.

Em virtude disso:

\begin{abstract}
A conciliação entre as duas exigências, aparentemente contraditórias, do reconhecimento da criança como sujeito de direito e do reconhecimento do direito dos pais de educar os filhos não pode deixar de requerer um novo modo de exercício das responsabilidades parentais. Tal novo modo de exercício deverá privilegiar a função educativa como principal linha de força das responsabilidades parentais e, nessa medida, adaptá-la ao reconhecimento do filho como sujeito de direitos dotado de uma autonomia progressiva. Assim, os pais, no desempenho da função educativa, deverão acompanhar o processo de desenvolvimento do filho, concedendo-lhe progressivamente cada vez mais e maiores espaços de autonomia, ou seja, dirigindo cada vez menos sua educação. Tal acompanhamento traduzir-se-á, por exemplo, no poder-dever de ouvir o filho relativamente a todos os assuntos que lhe digam diretamente respeito e no poder-dever de estimular sua participação no processo de decisão. (MARTINS, 2009, p.94).
\end{abstract}

Portanto, os limites do exercício da autoridade parental consistem na observação da autonomia progressiva da criança e do adolescente, bem como, em apurar qual seu melhor interesse para a situação. Não basta mais a imposição verticalizada da vontade dos pais. O menor como sujeito de direitos e possuidor de dignidade deve ter sua vontade respeitada na medida em que tenha discernimento para tomar as decisões referentes ao ato, ainda que contrarie seus pais ou que sua decisão consista em um 'erro'. Reforçamos a visão de que a intervenção paterna e materna deve se limitar à proteção necessária para o desenvolvimento do filho. Em caso de conflito, prevalece a vontade que atender ao melhor interesse do menor. 


\title{
4 O DIREITO À RECUSA DE TRATAMENTO MÉDICO COMO COMPONENTE DO EXERCÍCIO AO LIVRE DESENVOLVIMENTO DA PERSONALIDADE
}

Tratamento médico é o conjunto de meios, de qualquer tipo, farmacológico, cirúrgico ou físico, cuja finalidade é a cura ou o alívio de uma enfermidade ou seus sintomas após a elaboração de um diagnóstico por profissional competente. Trata-se de conceituação que abrange os mais diversos aspectos relacionados à saúde humana, compreendendo desde o uso de um comprimido para a dor de cabeça até uma complexa neurocirurgia.

O tratamento médico deve ser compreendido pelo paciente para que o mesmo forneça seu consentimento ou o recuse devidamente informado. Sobre as consequências da ausência de diálogo, Brunello Stancioli aponta que:

\begin{abstract}
A terceira forma de objetificação do sujeito é a reconstrução de seu ego. Através de todo um aparato linguístico, o paciente internaliza recomendações médicas. E o faz, pelo temor das consequências (veladas, sugeridas, supostamente graves), caso desobedeça ao profissional de saúde. Suporta, assim, passivamente, várias formas de tratamento, mesmo que lhes sejam desconhecidas ou desagradáveis. (STANCIOLI, 2004, p.25).
\end{abstract}

Assim "compreender um tratamento concreto implica compreender a natureza, os objetivos, os riscos, os efeitos secundários e as possíveis consequências do tratamento, assim como as consequências de não o fazer." (ABREU, 2012, p. 17).

A compreensão do tratamento médico é produto do dever de esclarecimento do profissional de saúde, previsto no Código de Ética Médica brasileiro: "é vedado ao médico Art. 34: Deixar de informar ao paciente o diagnóstico, o prognóstico, os riscos e os objetivos do tratamento, salvo quando a comunicação direta possa the provocar dano, devendo, nesse caso, fazer a comunicação a seu representante legal."

Tal dever consiste na obrigação do médico em informar ao paciente todos os aspectos inerentes ao tratamento ofertado, bem como alternativas e consequências possíveis. Ademais, exige que o profissional da saúde utilize linguagem clara e acessível para que o paciente realmente compreenda o que lhe está sendo apresentado. Neste sentido:

Esse requisito não se restringe, portanto, ao fato do profissional de saúde "passar" a informação ao paciente. A informação deve ser construída dialogicamente e não unilateralmente. Assim, não basta que o profissional relate os dados, mas que se comunique com o paciente de forma acessível. (SÁ, NAVES, 2015, p. 108). 
Uma vez esclarecido acerca dos riscos e benefícios do tratamento, o paciente, no exercício de sua autonomia, deve decidir se fornece seu consentimento. Este exercício, no âmbito da relação médico-paciente, recebe o nome de consentimento informado.

Deve-se buscar o real exercício da autonomia do paciente ao fornecer consentimento para intervenções médicas e cirúrgicas. A autonomia está presente quando observados os requisitos da informação, do discernimento e da ausência de condicionadores externos. A informação, conforme mencionamos, é obtida por meio do dever de esclarecimento do médico. O discernimento pode ser definido como a capacidade de compreender o que the é exposto e tomar uma decisão ciente dos riscos e possíveis resultados. Já a ausência de condicionadores externos são os vícios da vontade ou sociais. Admitem-se como condicionantes apenas aqueles oriundos da própria consciência do paciente (SÁ, NAVES, 2015, p. 108-109).

$\mathrm{O}$ ordenamento jurídico brasileiro tutela, a nível constitucional e infra, os direitos à vida, à saúde, à liberdade e, em especial, à dignidade da pessoa humana. Não há sobreposição hierárquica entre esses direitos, de modo que, em caso de conflito entre eles deve-se verificar qual deve prevalecer diante de um caso concreto.

Em relação à possibilidade de uma pessoa recusar tratamento médico, temos os arts. 11, 13 e 15 do Código Civil brasileiro. Interpretando-os de forma literal, pode-se entender que a recusa de tratamento médico não seria permitida neste ordenamento jurídico, pois seria um ato de disposição voluntária de um direito da personalidade (vida, integridade corporal). Contudo, não se pode admitir tal interpretação em um Estado Democrático de Direito, fundamentado na Dignidade da Pessoa Humana (art. $1^{\circ}$, III, CR de 1988).

João Baptista Villela ao analisar os supracitados dispositivos do Código Civil Brasileiro, aponta que:

Outro sério limite do Código na matéria é não ter distinguido entre titularidade e exercício, inscrevendo neste o que é atributo daquela. Ao dizer que o exercício dos direitos da personalidade não pode "sofrer limitação voluntária" (art. 11) o Código operou uma radical inversão: submeteu a pessoa aos direitos ao invés de pô-los ao serviço daquela. Esqueceu-se da advertência capital de Hermogeniano "Quum igitur homunem causa omne jus costitutum sit ${ }^{6}$ (...)”. (VILLELA, 2012, p.117).

Temos ainda o Enunciado 403 da V Jornada de Direito Civil, que interpreta do art. 15 do Código Civil à luz da inviolabilidade de crença:

403) Art. 15. O Direito à inviolabilidade de consciência e de crença, previsto no art. $5^{\circ}$, VI, da Constituição Federal, aplica-se também à pessoa que se nega a tratamento médico, inclusive transfusão de sangue, com ou sem risco de morte, em razão do tratamento ou da falta dele, des de que observados os seguintes critérios: a) capacidade civil plena, excluído o suprimento pelo representante ou assistente; b) manifestação de vontade livre, consciente e informada; e c) oposição que diga respeito exclusivamente à própria pessoa do declarante. 
Além do mais, a Portaria ${ }^{\circ} 1820$ de 2009, do Ministério da Saúde, ao trazer os direitos e deveres dos usuários do sistema de saúde aponta em seu art. $4^{\circ}$, parágrafo único, XI e XI, a possibilidade de recusar o tratamento recomendado pelo profissional da saúde. A Lei Estadual n 10241 de 1999, conhecida como Lei Mário Covas, dispõe sobre os direitos dos usuários do sistema de saúde do estado de São Paulo e permite em seu art. Art.2, VII, a recusa

de procedimentos diagnósticos ou terapêuticos. Com isso, temos uma abertura no sistema jurídico brasileiro para que o paciente, no exercício de sua autonomia, negue consentimento para tratamento de saúde.

Assim, o Direito não deve ser aplicado de forma rígida, literal, mas sim interpretado de acordo com as particularidades do caso concreto. Ademais a vida, em sua dimensão biográfica, não pode ser vista como um dever, mas sim como um direito. No âmbito do Direito Civil a Dignidade da Pessoa Humana se faz presente quando sua autonomia privada é garantida.

Deve ficar claro que:

\begin{abstract}
Não há nessas reflexões apologia ao autoextermínio, senão, ao contrário, valorização da vida, só é possível onde ela se instrumentaliza ao serviço da liberdade. A vida pela vida inscreve-se na ordem da natureza [...] Só a liberdade faz dela um valor caracteristicamente humano. Em outras palavras e em resumo, o que importa não é tanto a vida, mas o que fazemos dela. (VILLELA, 2012, p.121)
\end{abstract}

Portanto, a possibilidade de se recusar tratamento médico está em conformidade com o ordenamento jurídico brasileiro. Resta apurar esta questão em relação às crianças e aos adolescentes.

O Código Civil estabelece que a capacidade plena para o exercício pessoal dos direitos civis se dá quando a pessoa completa dezoito anos de vida (art. $5^{\circ}, \mathrm{CC}$ de 2002). Porém, o Direito, por não ser aplicado a situações imutáveis é constantemente construído por meio da prática argumentativa. Em virtude disso, podemos dizer que a presunção de incapacidade dos menores de dezoito anos não pode ser absoluta. Neste sentido, "sob a ótica biopsicológica, os parâmetros não são determinados de acordo com uma data específica, mas de acordo com mudanças psicológicas e fisiológicas variáveis que ocorrem em torno dessa idade.” (FIORELLI, MANGINI, 2015, p. 153).

\footnotetext{
${ }^{6}$ Algo como todo direito foi criado em razão do homem
} 
Conforme apontamos, a autonomia de crianças e adolescentes e seu desvencilhamento da autoridade parental ocorre de forma progressiva. A criança começa a tomar pequenas decisões cotidianas como a escolha do que vestir, com o que brincar e aos poucos a amplitude de tomadas de decisões aumenta, incluindo questões como escolha da profissão ou da religião. Ou seja, aos poucos o grau de compreensão aumenta junto com a complexidade das decisões a serem tomadas. Não é como se magicamente um dia, ao completar dezoito anos o sujeito adquirisse maturidade. Isso é algo construído.

Em relação ao tratamento médico, uma primeira possibilidade é negar que a recusa seja feita pela criança ou pelo adolescente. A justificativa é a preservação de sua autonomia futura, para que, devidamente capaz e com discernimento, faça suas próprias escolhas. (SÁ, NAVES, 2015, p. 131).

Contudo, apenas negar essa possibilidade não é algo compatível com atual momento do Direito, de sua reconstrução diante das peculiaridades de um caso concreto. Não se deve olvidar que há casos, como os de Hannah Jones e de Reece Puddington (tratados na introdução), em que, apesar da tenra idade, apresentavam o discernimento necessário para a tomada de decisões médicas. Novamente, aponta-se o fato de que a biografia não é menos importante que à biologia e a situação deve ser analisada de forma especial:

\footnotetext{
A idade não importa se menor, madura ou senil, não incide de per si, sobre a aptidão para titularidade das situações subjetivas. O seu efetivo exercício pode ser limitado ou em parte excluído, não a partir de predeterminadas, abstratas, rígidas e às vezes, arbitrárias avaliações ligadas às diversas fases da vida, mas, sim com base na correlação, a ser avaliada atentamente, entre a natureza do interesse no qual se substancia a concreta situação e a capacidade intelectiva e volitiva. Deve-se verificar a real capacidade de efetuar e de realizar as escolhas e comportamentos correlatos às situações subjetivas interessadas. (PERLINGIERI, 2002, p. 167).
}

O conceito de competência é relevante para o tema abordado. "A competência se traduz na mobilização de recursos cognitivos e emocionais necessários para o paciente tomar uma decisão autônoma em face de problema relacionado com seu estado de saúde" (RIBEIRO, 2010, p.170), sendo esta a forma mais adequada para se apurar o discernimento nas questões existenciais, pois a tradicional capacidade de agir foi pensada para situações patrimoniais. A competência para tomada de decisões médicas pode ser aplicada nas situações envolvendo menores de idade, sendo os parâmetros elaborados no Caso Gillick formas de se apurar a competência. 
Os critérios levantados pelo caso se aplicam às situações de consentir em tratamento de cunho de educação sexual, mas podem ser utilizados como parâmetros para auxiliar a equipe médica e caso necessário, o juiz, a decidir sobre a possibilidade de recusa de tratamento médico.

Adaptando o teste de Lorde Scarman, o jovem seria avaliado por equipe multidisciplinar composta pelos médicos responsáveis pelo tratamento convencional e por psicólogos especializados nesta faixa etária. A decisão seria fruto de um consenso desta equipe e caso isso não fosse possível, a questão seria levada ao judiciário. A alteração significativa seria distribuir o 'poder' de decisão que era apenas do médico para uma equipe capacitada. Além da presença da competência para tomada de decisões médicas, deve ser avaliada ainda a complexidade da doença, os riscos e possíveis consequências da recusa do tratamento. A adaptação das Fraser guidelines seria feita de modo similar, apenas substituindo as expressões relacionadas ao tratamento contraceptivo pelo relacionado ao da doença posta em análise.

Presente a competência necessária para recusa de tratamento médico a autonomia da criança e do adolescente deve ser respeitada em prol de seu melhor interesse. Ademais, o art. 12 da Convenção dos Direitos da Criança, devidamente ratificada pelo Governo brasileiro e os arts. 15 e 16 do Estatuto da Criança e do Adolescente asseguram aos menores o direito de participação na tomada de decisões que lhes digam respeito, conforme mencionamos acima.

Dessa forma, a recusa de tratamento médico por incapaz em razão de idade encontra fundamentação compatível com a ordem constitucional vigente. Deve ser analisada pelo judiciário de forma a considerar o desenvolvimento intelectual e a capacidade de compreensão das consequências de sua recusa, bem como, se não há imposição de seus responsáveis nesta escolha. Voltando a Adam Henry, a imposição da transfusão de sangue, como fez a juíza Fiona ao jovem rapaz afigura-se desrespeito à sua biografia, à sua autonomia em construção e, em especial, à sua dignidade.

\section{NOTAS CONCLUSIVAS}

O Caso Gillick é paradigmático por se tratar de uma decisão que permitiu que uma pessoa menor de dezesseis anos, desde que, com inteligência e discernimento suficientes (Lorde Scarman e Lorde Fraser), opte por tomada de decisões acerca de métodos contraceptivos, ainda que contra a vontade de seus representantes legais. 
Este Case aborda ainda os limites das decisões tomadas pelos responsáveis e que causam impacto na vida dos filhos, por isso se fez pertinente o estudo da autoridade parental e de seus limites para questões de cunho existencial. Concluímos que estes são o princípio do melhor interesse do menor e sua autonomia progressiva. Em outras palavras, a autoridade dos pais com os filhos é limitada na medida em que estes adquirem o discernimento necessário para a prática dos atos da vida civil.

Ao analisarmos o ordenamento jurídico brasileiro, de forma sistêmica, não encontramos óbice para a recusa de tratamento médico em virtude da inexistência de um dever de viver. A vida deve se dar de forma digna, do nascimento à morte.

O Caso Gillick não aborda a recusa de tratamento médico. Porém, transpondo-o para o Direito Brasileiro podemos enxergá-lo como um marco para garantia da autonomia na tomada de decisões médicas. O primeiro aspecto a ser verificado é se há inteligência e discernimento suficientes para o jovem enfrentar a situação. A autonomia jurídica vai depender do maior ou menor amadurecimento psicológico da criança e do adolescente.

Haverá situações em que a criança ou o adolescente estará pronto para decidir; outras, o jovem não estará pronto para qualquer tomada de decisão; nesse caso, a decisão ficará a cargo dos representantes legais no melhor interesse da criança ou do adolescente. $\mathrm{E}$ ainda outras situações em que o menor poderá participar do processo de decisão, necessitando do acompanhamento dos responsáveis legais.

Não se pode esquecer a pessoa concreta. Não pretendemos com este trabalho impor uma responsabilidade que a criança e o adolescente não podem suportar. Por isso, ressaltamos a importância de se aplicar o Direito diante de um caso concreto. A rigidez normativa pode violar a dignidade e a autonomia da criança ou do adolescente que possui competência para tomada de decisões. De outro lado, a ampla flexibilização poderia criar um peso insuportável ao menor que não tem condições emocionais para tomar tamanha decisão. A temática da recusa de tratamento médico em crianças e adolescentes necessita de um equilíbrio jurídico para que se tome a decisão mais adequada ao caso concreto, levando em consideração o discernimento do menor (verificado pela Competência de Gillick), a gravidade da doença, bem como as consequências de não se tratar a enfermidade.

Em outras palavras, a restrição da lei brasileira tem um papel relevante de proteção da criança e do adolescente, assim como tem a autoridade parental. $\mathrm{O}$ que concluímos neste trabalho é que a criança e o adolescente, sempre que possível, devem participar das decisões que impactam em sua vida, incluindo a recusa de tratamento médico, desde que presente a maturidade necessária (respeito à sua autonomia progressiva e ao melhor interesse do menor). 


\section{REFERÊNCIAS}

ABREU, Catarina Maria Pedro. As regras de obtenção do consentimento para intervenções médicas em menores: o significado da Gillick competence e a possível adoção da figura em Portugal. 2012. 47f. Dissertação (Mestrado) - Universidade Católica Portuguesa. Programa de Pós Graduação em Direito, Lisboa.

BRASIL. Constituição (1988). Constituição da República Federativa do Brasil. Brasilia, DF: Senado Federal, 1988.

. Estatuto da Criança e do Adolescente. Lei no 8.069, de 13 de julho de 1990. Dispõe sobre o estatuto da criança e do adolescente e dá outras providências. Brasilia, DF: Senado Federal, 1990.

Convenção sobre os Direitos da Criança. Decreto $n^{\circ}$ 99.710, de 21 de novembro de 1990. Promulga a convenção sobre os direitos da criança. Brasîlia, DF: Senado Federal, 1990.

Código Civil de 2002. Lei n ${ }^{\circ}$ 10.406, de 10 de janeiro de 2002. Institui o código civil. Brasília, DF: Senado Federal, 2002.

Conselho Federal de Medicina. Código de ética médica. Resolução CFM nº 1931 de 24 de setembro de 2009. Brasília, 2009.

DWORKIN, Ronald. Domínio da vida: aborto, eutanásia e liberdades individuais. Trad. Jefferson Luiz Camargo. $2^{a}$.ed. São Paulo: Martins Fontes, 2009.

FERREIRA, Ana Luiza Veiga ; VIEIRA Marcelo de Mello. O melhor interesse e a autonomia progressiva de crianças e adolescentes. Revista de Direito da Infância e da Juventude, v. 2, p. 233-259, 2013.

FIORELLI, José Osmir. MANGINI, Rosana Cathaya Ragazzoni. Psicologia jurídica. 6.ed. São Paulo: Atlas, 2015.

FORTIN, Jane. Children's rights and the developing law. 3.ed. Nova York: Cambridge University Press, 2009.

Gillick v West Norfolk and Wisbech Area Health Authority [1985] 3 All ER 402. Disponível em: <http://www.cirp.org/library/legal/UKlaw/gillickvwestnorfolk1985/> Acesso em: 10 de jul. de 2015 .

Jornadas de direito civil I, III, IV e V: enunciados aprovados. Coordenador científico AGUIAR JÚNIOR. Ministro Ruy Rosado de. Brasilia: Conselho da Justiça Federal, Centro de Estudos Judiciários, 2012.

MARTINS, Rosa. Responsabilidades parentais no século XXI: a tensão entre o direito de participação da criança e a função educativa dos pais. In: Cuidado e vulnerabilidade. PEREIRA, Tânia da Silva; OLIVEIRA, Guilherme de (Coord.). São Paulo: Atlas, 2009.

McEWAN, Ian. A balada de Adam Henry. São Paulo: Companhia das Letras, 2014. 
Ministério da Saúde. Portaria $n^{\circ} 1.820$ de 13 de agosto de 2009. Dispõe sobre os direitos e deveres dos usuários da saúde. Brasília, 2009.

PARRY, Lizzie. Brave bucket-list boy, 11, loses six-year-cancer battle, days after urging followers to 'keep donating for other children like me. Mail on line. Londres. 21 de maio de 2014. Disponível em: <http//www.dailymail.co.uk/health/article-2634915/Please-donationscoming-Brave-bucket-list-boys-selfless-final-message-help-loses-fight-cancer.html $>\quad$ Acesso em: 20 de jul. de 2015 .

PERLINGIERI, Pietro. Perfis de direito civil. Trad. Cicco, Maria Cristina de. 2.ed. Rio de Janeiro: Renovar, 2002.

RIBEIRO, Gustavo Pereira Leite. A competência da criança e do adolescente para o exercício do direito à recusa de tratamento médico. 2010. 281f. Tese (Doutorado) Pontifícia Universidade Católica de Minas Gerais, Programa de Pós-Graduação em Direito, Belo Horizonte.

RODOTÀ. Stefano. La vida y las reglas: entre el derecho y el no derecho. Trad. Andrea Greppi. Madri: Editorial Trota, 2010.

SÁ, Maria de Fátima Freire de. MOUREIRA, Diego Luna. Autonomia para morrer eutanásia, suicídio assistido e diretivas antecipadas de vontade. 2.ed. Belo Horizonte: Del Rey, 2015.

SÁ, Maria de Fátima Freire de; NAVES, Bruno Torquato de Oliveira. Manual de Biodireito. Belo Horizonte: Del Rey, 2015.3 ${ }^{\mathrm{a}}$. ed.revista. atualizada e ampliada.

São Paulo. Lei estadual no 10.241 de 18 de março de 1999. Dispõe sobre direitos dos usuários dos serviços de saúde. Assembleia Legislativa, São Paulo, 1999.

TEIXEIRA, Ana Carolina Brochado. Família, guarda e autoridade parental. Rio de Janeiro: Renovar, 2005.

TEIXEIRA, Ana Carolina Brochado; PENALVA, Luciana Dadalto. Autoridade parental, incapacidade e melhor interesse da criança: uma reflexão sobre o caso Ashley. Revista de Informação Legislativa, Brasilia, a. 45, n. 180, p. 293-304, out./dez 2008.

VILLELA, João Baptista. O código civil brasileiro e o direito à recusa de tratamento médico. In. Bioética e direitos fundamentais. GOZZO, Débora. LIGIERA, Wilson Ricardo. (Coord.) São Paulo: Saraiva, 2012. 